\title{
Pseudomonas aeruginosa porphobilinogen synthase assembly state regulators: hit discovery and initial SAR studies
}

\author{
Allen B. Reitz, ${ }^{* a}$ Ursula D. Ramirez, ${ }^{\mathrm{b}}$ Linda Stith, ${ }^{\mathrm{b}}$ Yanming Du, ${ }^{\mathrm{a}}$ Garry R. Smith, ${ }^{\mathrm{a}}$ and \\ Eileen K. Jaffe, ${ }^{*}, \mathrm{~b}$ \\ ${ }^{a}$ Fox Chase Chemical Diversity Center, Inc., Pennsylvania Center for Drug Discovery, \\ Pennsylvania Biotechnology Center, Doylestown, PA 18902 USA \\ ${ }^{b}$ Fox Chase Cancer Center, 333 Cottman Ave., Philadelphia, PA 19111 USA \\ E-mail : $\underline{\text { AReitz@fc-cdci.com, Eileen.Jaffe@fccc.edu }}$
}

This paper is dedicated to Bruce and Cynthia Maryanoff for mentorship and in recognition of their distinguished careers and contributions to science

\begin{abstract}
Porphobilinogen synthase (PBGS) catalyzes the first common step in the biosynthesis of the essential heme, chlorophyll and vitamin $B_{12}$ heme pigments. PBGS activity is regulated by assembly state, with certain oligomers exhibiting biological activity and others either partially or completely inactive, affording an innovative means of allosteric drug action. Pseudomonas aeruginosa PBGS is functionally active as an octamer, and inactive as a dimer. We have identified a series of compounds that stabilize the inactive $P$. aeruginosa dimer by a computational prescreen followed by native PAGE gel mobility shift analysis. From those results, we have prepared related thiadiazoles and evaluated their ability to regulate $P$. aeruginosa PBGS assembly state.
\end{abstract}

Keywords: Protein assembly state, porphobilinogen synthase (PBGS), Pseudomonas aeruginosa

\section{Introduction}

Drug discovery research is a difficult but worthwhile human endeavor. The level of new compounds introduced into therapy remains stagnant, having returned to the historic levels seen in the 1950s. ${ }^{1}$ New approaches involving innovation in treatment may add great hope for success in the future. In 2009, only 26 new molecular entities (NMEs) were approved by the U.S. Food and Drug Administration (FDA), ${ }^{2}$ even though spending on drug discovery research has increased tremendously during the previous decades. The current unexpectedly low level of productivity in drug discovery research has occurred even though our understanding of the molecular basis of disease and toxicology had increased dramatically and important new enabling technologies have been developed and validated. Therefore, it is gratifying to appreciate 
and recognize the scientific contributions of Bruce and Cynthia Maryanoff, who have managed to develop and maintain exceptionally strong scientific careers while at the same time contributing directly to the introduction of new NMEs into therapy such as the anticonvulsant topiramate. ${ }^{3}$ NMEs have historically originated in large pharmaceutical companies, with $50 \%$ of them coming from only 21 companies since 1950. ${ }^{1}$ However, in recent years, more NMEs have emerged from small companies. ${ }^{1}$ Further, drug discovery research is moving from a traditional model involving a linear transition of functions from target identification to introduction into the market, to more networked relationships involving public private partnerships between academic groups and biotechnology or pharmaceutical companies. However, the important transition points in drug discovery research remain the same: hit identification and triage, lead declaration, and transition into preclinical development. We here describe an innovative approach for the identification of screening hits at an allosteric protein-protein interface. We performed compound library screening after a computational prescreen, and identified hits that have the potential to selectively regulate the assembly state and function of a key enzyme in Pseudomonas aeruginosa. We also prepared and evaluated a secondary library based upon the hits identified to explore initial structure activity relationships.

$P$. aeruginosa is a Gram-negative opportunistic pathogen exploiting lapses in host defenses. This pathogen causes urinary tract infections, dermatitis, respiratory system infections, bacteremia, bone and joint infections, gastrointestinal infections and a variety of systemic infections, particularly in patients with severe burns and in cancer and immuno-suppressed AIDS patients. ${ }^{4}$ P. aeruginosa is mainly a nosocomial infection and is particularly serious for patients hospitalized with burns, cancer, and cystic fibrosis where the fatality rate is $\sim 50 \%{ }^{5}$ $P$. aeruginosa infections are the fourth most commonly observed in U.S. hospitals with an incidence of $\sim 10 \%$ of all nosocomial infections, and are associated with low susceptibility to antibiotic treatment largely due to multidrug efflux pumps associated with antibiotic resistance genes. Given the severity and incidence of $P$. aeruginosa infection, new means of treatment that are not subject to antibiotic efflux would be valuable additions to current therapy.

Jaffe and co-workers have recently described an unexpected quaternary structure dynamic that allows for the identification of new drug targets and promotes an entirely new paradigm in drug discovery research. ${ }^{6-8}$ In this approach, a specific quaternary structure assembly is stabilized, which is chosen based on the known functional role of that assembly. The quaternary structure dynamic targeted is characteristic of proteins termed, "morpheeins", homo-oligomeric proteins that dissociate, change conformation in the dissociated state, and reassemble to a structurally and functionally distinct assembly state. ${ }^{6}$ Chemical probes and drug candidates bind to the assembly-specific surface cavities distant from the active sites. The amino acids in the oligomer-specific, small molecule binding site are often phylogenetically variable, allowing for greater specificity of action across species. The unique characteristic of such a surface site is that it lacks the evolutionary requirement for conservation that is characteristic of active sites. We have undertaken a series of docking studies that target and exploit the surface cavities specific to a particular oligomeric component of an equilibrium of quaternary structure 
assemblies characteristic of a morpheein. ${ }^{7,8}$ In this way, we can inhibit the function of a protein by stabilizing an inactive assembly state by binding to a site or pocket in the protein-protein interface particular to that inactive oligomer. In related work, regulation of assembly state and function of a protein by a small molecule has been demonstrated for transthyretin using flufenamic acid and related compounds. ${ }^{9}$

Tetrapyrroles play a universally central role in energy metabolism throughout all phyla, although the roles of these essential cofactors such as heme, chlorophyll, siroheme, B12, and F430 differ dramatically among aerobic, photosynthetic, and methanogenic organisms. Porphobilinogen synthase (PBGS, EC 4.2.1.24), also known as 5-aminolevulinic acid dehydratase (or ALAD), catalyzes the first common step in the biosynthesis of the tetrapyrrole pigments (Eq. 1). The tetrapyrrole biosynthetic pathway in humans is controlled predominantly at the level of the biosynthesis of the PBGS substrate 5 -aminolevulinic acid (ALA), ${ }^{10}$ but there are additional control points for the common tetrapyrrole biosynthetic pathway in other organisms. ${ }^{11}$ Early studies on plant- and some bacterial-PBGS revealed a protein concentrationdependence to the enzyme's specific activity that is consistent with the co-existence of a high activity oligomer of higher stoichiometry, and a less active oligomer of lower stoichiometry. ${ }^{12,13}$ The current interpretation is that interconversion among active octamers and inactive dimers and inactive hexamers explains the protein concentration-dependent specific activity. ${ }^{6}$ This protein concentration-dependent specific activity is seen for PBGS from Pseudomonas aeruginosa and for many other pathogen targets.

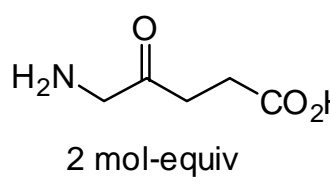

5-Aminolevulinic acid
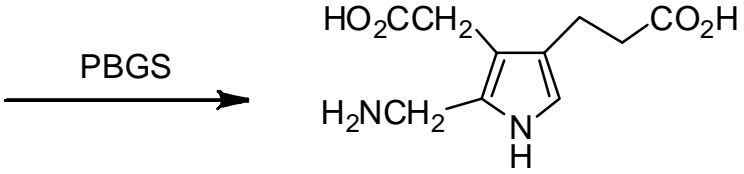

Porphobilinogen
(1)

The active sites of most PBGS contain identical residues, with the exception of a metal binding site that differs between humans, plants, and most human pathogens. ${ }^{14}$ The variation in this metal binding site is a very small component of the active site, and is not likely to provide sufficient structural differences to yield species-selective inhibitors using computational docking to the active site. However, PBGS from Pisum sativum and humans exist in a dynamic equilibrium of oligomeric forms including a high-activity octamer, a low-activity hexamer, and two conformations of a low-activity dimer, one that is conformationally competent for assembly to the octamer and another for assembly to the hexamer. ${ }^{15-17}$ Not all PBGS populates the hexameric assembly. For example, Pseudomonas aeruginosa PBGS exists in a dynamic equilibrium consisting of only high-activity octamer and low-activity dimer forms.

The structural differences between octamer, hexamer, and dimer can explain the functional differences between PBGS oligomers. In particular, the octameric assembly contains a specific subunit-subunit interface that stabilizes the "closed" conformation of a mobile active site lid. In the hexamer, the active site is exposed to solvent, and PBGS activity requires high substrate 
concentration because the $K_{\mathrm{m}}$ determining substrate is stabilized by the closed lid and also requires high $\mathrm{pH}$ to facilitate Schiff base formation. The existence of PBGS as an ensemble of alternate, non-additive quaternary structures was first suggested by examination of the X-ray crystal structure of a naturally occurring low-activity variant of human PBGS. ${ }^{18}$ This variant, F12L, assembles into a homo-hexamer, which is in stark contrast to the X-ray crystal structure of the homo-octameric assembly for the wild type human protein and the octameric assemblies of all other PBGS crystal structures. ${ }^{19-21}$ We have already identified compounds that modulate the PBGS assembly state in such a way as to stabilize the inactive form found in $P$. sativum, human, and Yersinia enterocolotica. ${ }^{8,22,23}$

\section{Results and Discussion}

The inactive component of the quaternary structure equilibrium for PaPBGS is the dimer. Therefore, we docked the entire collection of commercially-available compounds from Life Chemicals, Inc. with the PaPBGS dimer using the Schrodinger docking software GLIDE. ${ }^{8,2}$ For this dimeric target, which derives from the dissociation of the PaPBGS octamer, we considered the hydrophilicity and hydrophobicity of the exposed surfaces, in defining the docking box. For reasons that remain unclear, the equilibrium for PBGS from some species, such as PaPBGS, appears to involve only octamers and dimers, and we do not know if the dimer has more than one native conformation. Therefore, for PaPBGS small molecules have been sought to disrupt assembly of dimers into octamers. For this approach, the targeted region on the protein surface is between pro-octamer dimmers as described previously. ${ }^{25}$ For the dimeric target, where the small molecule sought would block octamer assembly, we also used a large docking box. The region targeted for docking to the dimer lies at the interface of two pro-octamer dimers. We sought compounds that must both dock to this surface and disrupt key interactions at the PPI such that octamer formation becomes less energetically favorable.

Seventy-three of the compounds purchased on the basis of the computational prescreen were purchased and tested by native PAGE for their ability to shift the quaternary structure equilibrium of $\mathrm{PaPBGS}$ from predominantly octamer to predominantly dimer after incubation for 30 mins at $37^{\circ} \mathrm{C}$. Seven compounds visibly increased the percent dimer, and four of these (1-4) showed substantial conversion of octamer to dimer, and two of these four shifted the equilibrium to greater than $50 \%$ dimer. The gel shift data and structures of the four compounds that showed the highest increase in percentage dimer on the gels are shown in Figure $1 \mathrm{~A}$, and the docked poses of these compounds are shown in Fig. 1B. Unlike the hexamer stabilizing agents described above, the PaPBGS dimer stabilizing compounds did not inhibit PaPBGS during an activity assay to a level commensurate with their percentage shift to dimer by native PAGE. We have shown that addition of substrate to a PBGS quaternary structure equilibrium acts to stabilize the octamer. ${ }^{8,23,26}$ Substrate binding at the active site causes molecular interactions that stabilize a closed conformation for a dynamic loop that serves to isolate the active site from bulk solvent. When this loop is in its closed conformation, the number of subunit-subunit contacts in an 
octamer specific subunit interface increases, thus drawing the quaternary structure equilibrium toward the octamer. Figure 2 shows that although compounds $\mathbf{3}$ and $\mathbf{4}$ significantly stabilize the dimer, the addition of an equimolar amount of the PBGS substrate 5-aminolevulinic acid (ALA) is sufficient to draw the equilibrium back to the octamer. Thus, these compounds do not bind sufficiently tightly to prevent octamer assembly in the presence of substrate. Therefore, the dimer stabilizing compounds $\mathbf{1 - 4}$ are expected to require substantial redesign before they are advanced to lead status in drug discovery. Nevertheless, they represent the first agents that have been identified to regulate the assembly state of PaPBGS and serve as a starting point for the design of subsequent probe libraries to explore the functional consequences of this dimeroctamer equilibrium.

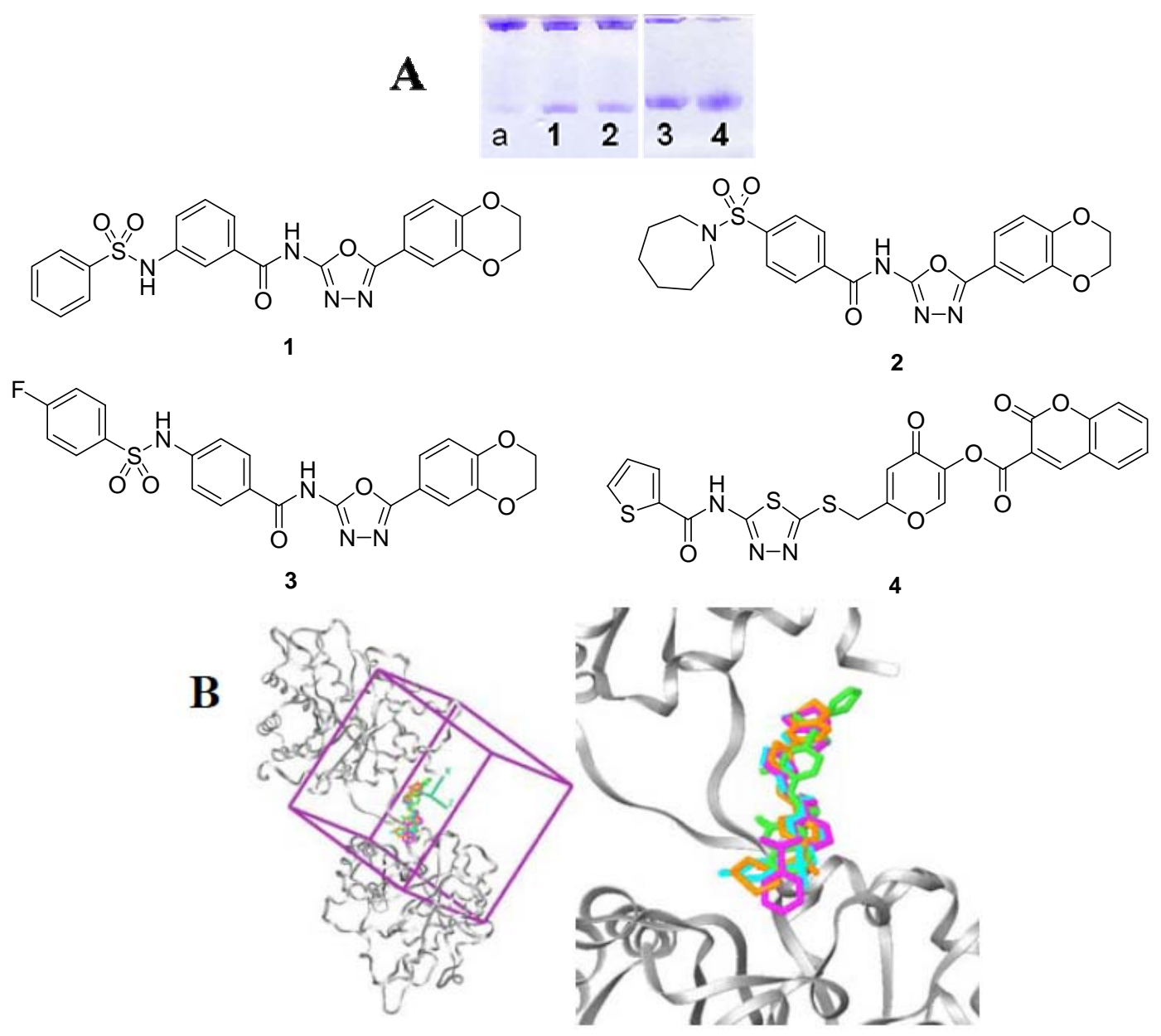

Figure 1. PaPBGS dimer-stabilizing compounds. (A) PaPBGS $(1.14 \mathrm{mg} / \mathrm{mL})$ was incubated for 30 mins at $37^{\circ} \mathrm{C}$ with DMSO only or with one of four dimer-stabilizing compounds (1-4, $2 \mathrm{mM}$; a is no compound added) dissolved in DMSO. Samples were resolved on 20\% polyacrylamide native PhastGels. Octameric PaPBGS is the upper band, and dimeric PaPBGS is the lower band. 2-Dimensional structural representations of the four most potent PaPBGS dimer-stabilizing compounds. (B) Overlay of ribbon diagram of PaPBGS pro-octamer dimer and stick figures of 
docked poses of $\mathbf{1}$ in magenta, $\mathbf{2}$ in cyan, $\mathbf{3}$ in orange, and $\mathbf{4}$ in green. The panel on the left shows the target with the docking box indicated in magenta; the panel on the right shows a close up of the same orientation.

Interestingly, all seven of the compounds that stabilized the PaPBGS dimer docked in the same region and had similar poses. Figure 1B shows the location of 1-4; the other three overlay these very closely (not shown). Selection criteria for dimer stabilizing compounds can be improved in several ways. Selection of the PaPBGS compounds included a rudimentary estimate of the compound's potential to disrupt the PPI, based solely on the residues to which the compounds dock on the one surface of the PPI to which we docked. In our initial attempt to find compounds that block PaPBGS octamer formation, we did not evaluate the impact of binding to the other side of the PPI. Thus, it is conceivable that we could find compounds that increase, or at least do not significantly decrease, the affinity of the PPI. Docking the same set of compounds to the other surface of the PPI could provide a starting point for such an evaluation, and might also allow identification of compounds whose effects potentiate one another by binding to two different faces of the PPI. A simple visual inspection to evaluate the poses of the molecules with two dimers bound as they are in the octameric crystal structure is another approach to evaluating the potential of a compound, as docked, to disrupt the PPI interactions. More rigorous methods could include individual alanine substitutions for interacting residues followed by energetic calculation of the PPI interactions; this would allow quantification of the contribution of individual residues to the PPI. This information could then be applied to the selection of compounds with the greatest potential to disrupt the interface. This approach would improve the rigor of our approach and is expected to improve the potency of discovered hits.

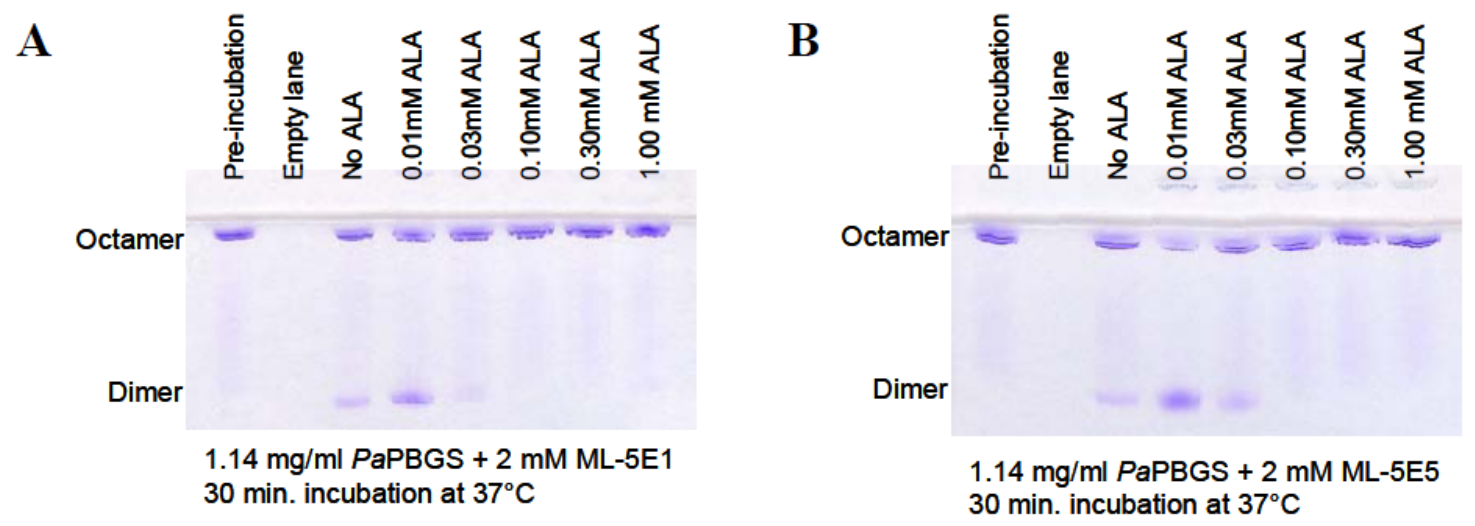

Figure 2. Addition of substrate (ALA) to PaPBGS incubated with two most potent dimerstabilizing compounds draws the equilibrium back to octamer. PaPBGS $(1.14 \mathrm{mg} / \mathrm{mL})$ was incubated for 30 mins at $37^{\circ} \mathrm{C}$ with $2 \mathrm{mM}$ of (A) 3 (ML-5E1) or (B) 4 (ML-5E5) in the absence of ALA or in the presence of varying amounts of ALA as labeled. No sample was loaded into lane 2. 


\section{Chemistry}

In order to probe the relation of structure on function, based upon the initial hits from the computational pre-screen and compound testing, we initially prepared a series of analogs of $\mathbf{4}$ lacking the pyrone and chromone functionalities. The molecular weight of 4 (MW 539.6) is relatively high for drug suitability, and ligand efficiency or the ratio of potency to size, which is an important criteria for early library hit triage and evaluation, is relatively poor. ${ }^{27}$ Replacement of the pyrone and chromone with smaller groups, if potency could be retained, would allow for greater flexibility in modifying the amidothiophene while maintaining suitable physical properties and molecular weight. The required 5-amino-[1,3,4]thiadiazole-2-thiol 5 is readily available commercially, and, and this intermediate can be readily converted into a series of diverse compounds in order to explore the relation of structure to function rapidly.

A series of 2-amino-5-sulfanyl-1,3,4-thiadiazole derivatives has been described previously. ${ }^{28}$ In that report, the compounds were first selectively $S$-alkylated followed by $N$-alkyation or $N$ acylation. Here, we sought to initially make the amidothiophene intermediate $\mathbf{6}$, followed by alkylation with a series of benzyl- or alkyl- halides in a parallel fashion to expedite the synthesis of the desired products 7 (Scheme 1). Acylation of 5-amino-[1,3,4]thiadiazole-2-thiol 5 with either thiophene-2-carbonyl chloride and base, or with thiophene-2-carboxylic acid under EDC/HOBt coupling conditions, afforded the desired intermediate $\mathbf{6}$. Isolation of pure $\mathbf{6}$ was often difficult because of poor aqueous solubility associated with both $\mathbf{5}$ and $\mathbf{6}$. Moreover, intermediate $\mathbf{6}$ can dimerize to disulfide $\mathbf{8}$. While reduction of disulfide $\mathbf{8}$ was straightforward, the immediate use of the free thiol $\mathbf{6}$ was often operationally cumbersome.

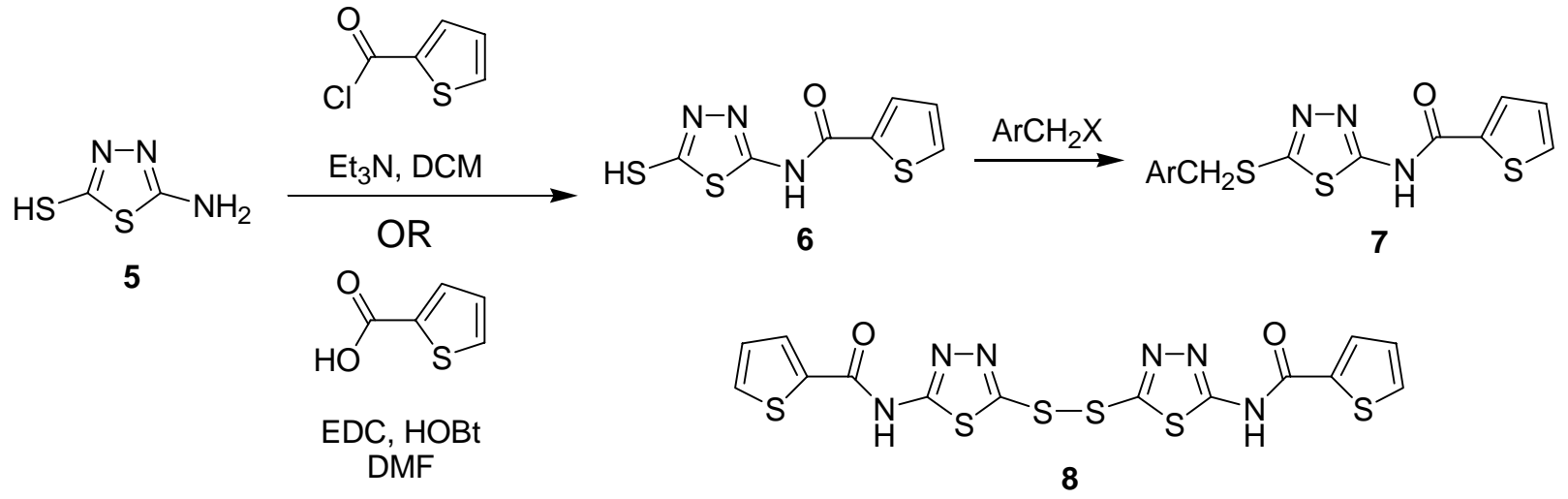

\section{Scheme 1}

We improved the preparation of thiadiazoles 7 by intentionally over-acylating $\mathbf{5}$ with thiophene-2-carbonyl chloride, providing the thioester amide 9 (Scheme 2). Thioester 9 was then hydrolyzed with lithium hydroxide to give the lithium salt of the intermediate 6 (Li-6). Subsequent quenching of Li-6 with benzyl halides provided the desired products 7a-l in 50-95\% yields. Since we sought to replace the chromone-pyran-ester, aromatic substitution seemed appropriate for the design of $\mathbf{7 a - 1}$. We kept the methylene linker, and replaced the aromatic 
portion with a series of aryl- and bi-aryl analogs with an overarching goal of understanding the chemical space which that end of the molecule occupies. Several methoxy- and sulfonylcontaining groups, as well as 5-membered ring heterocycles, were incorporated to potentially mimic the hydrogen bond acceptors present in $\mathbf{4}$. Also we sought evaluate diversity amongst the heterocycles examined, so that oxazole-, isoxazole-, thiazole- and pyrazole-5-membered rings were included.<smiles>Nc1nnc(S)s1</smiles>

5

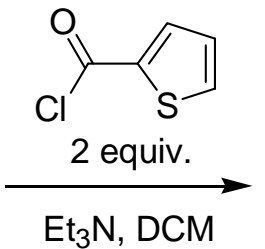

$\mathrm{Et}_{3} \mathrm{~N}, \mathrm{DCM}$<smiles>O=C(Nc1nnc(SC(=O)c2cccs2)s1)c1cccs1</smiles>

9

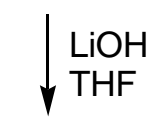

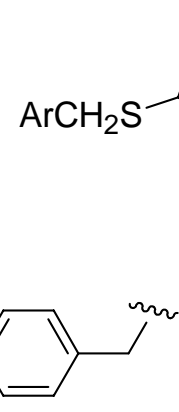

$7 a$<smiles>CCCc1oc(-c2ccccc2F)nc1C</smiles><smiles>CCCc1ccc(F)cc1Cl</smiles>

$7 g$<smiles>Clc1ccc(-c2nc(C[Te][Te])cs2)cc1</smiles>

7j<smiles>CCCCCc1nccc(OC)c1OC</smiles>

7b<smiles>CCCc1c(-c2c(Cl)cccc2Cl)noc1C</smiles>

$7 e$<smiles>CCCc1cccc(Oc2ccc(F)cc2)c1</smiles>

7h<smiles>FC(F)(F)c1ccc(-c2nc(CI)cs2)cc1</smiles>

7k<smiles>CCCc1ccc(-n2cccn2)cc1</smiles>

7c<smiles>CCc1cn2ccc(C)cc2n1</smiles>

$7 f$<smiles>Cc1nc(C[Te])cs1</smiles><smiles>CCCc1ccc(C(=O)Nc2cc(C)on2)cc1</smiles>

7I

\section{Scheme 2}




\section{Pharmacology}

Compounds $7 \mathbf{a}-\mathbf{l}$ were tested for their ability to influence the PaPBGS dimer-octamer assembly state equilibrium (Figure 3). None of the new compounds promoted the effective stabilization of the dimer, as did $\mathbf{4}$ (lane 2). However, compounds $\mathbf{7 a}$ and $\mathbf{7 b}$ showed the greatest extent of dimer (lanes 5 and 6, respectively), similar to when nothing was added (lane 3). Many of the

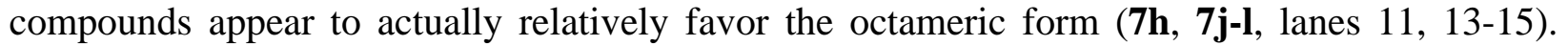
These results suggest a requirement to incorporate a relatively-extended substructure, as for the chromone of $\mathbf{4}$, in order to promote PaPBGS dimer stabilization.

\section{$\begin{array}{llllllllllllll}1 & 2 & 3 & 4 & 5 & 6 & 7 & 8 & 9 & 10 & 111213 & 14 & 15\end{array}$}

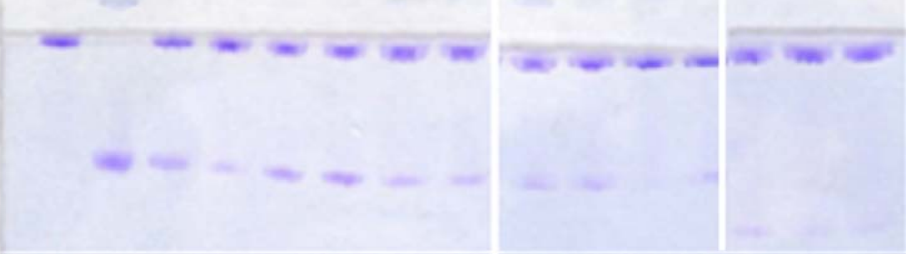

Figure 3. New thiadiazoles 7a-l tested for their effects on the PaPBGS dimer-octamer equilibrium.

PaPBGS (1.14 mg/mL) was incubated for 30 mins at $37^{\circ} \mathrm{C}$ with $2 \mathrm{mM}$ of $7 \mathrm{a}-\mathrm{l}$ (dimer, bottom; octamer, top). Legend for lanes: (1) pre, no incubation, (2) 4, (3) nothing added, (4) DMSO, (5) 7a, (6) 7b, (7) 7c, (8) 7d, (9) 7f, (10) 7g, (11) 7h, (12) 7i, (13) 7j, (14) 7k, (15) 7l.

\section{Conclusions}

Alteration of the protein assembly state offers a novel means for allosteric drug action. Here we have described a series of oxadiazoles and thiadiazoles that stabilize dimeric $P$. aeruginosa porphobilinogen synthase (PBGS) relative to the octameric form. These compounds were identified by a computational pre-screen of a large virtual library followed by evaluation of purchased compounds for their effects upon PBGS assembly state using native PAGE gel-shift analysis. An additional subset of 12 new thiazoles prepared based on the screening exercise revealed some $\mathbf{7 h}, \mathbf{7 j - 1}$ that appear to give the octameric form nearly exclusively. These added structure activity relationship trends help to define the structural parameters involved in $P$. aeruginosa PBGS assembly state regulation. We have found that regulation of the activity of PBGS is dependent upon the assembly state of the protein, in which certain forms are functionally active, and others not. We predict that regulation of enzyme function by control of non-additive assembly states in vivo may be common throughout nature and protein class, termed the morpheein model of allostery. ${ }^{6}$ We also consider the fact that it may be possible to inhibit the function of an essential protein or enzyme in a pathogen without interfering with the 
corresponding target in the host, providing a new means for allosteric anti-infective drug action. Therefore, application of the morpheein model of allostery to drug discovery may provide novel anti-infective therapy on a case-by-case basis depending on the differential regulation of protein assembly state in the pathogen $v$ s. the host.

\section{Experimental Section}

General. All reagents were purchased from Fisher Scientific (Acros) and used without purification. ${ }^{1} \mathrm{H}$ - NMR spectra were obtained on either a Bruker 500 - or $400-\mathrm{MHz}$ NMR or a Varian 300-MHz NMR. Melting points $\left({ }^{\circ} \mathrm{C}\right)$ were determined using an MPA100 OptiMelt Melting Point Apparatus, and are uncorrected. Analytical thin-layer chromatography (TLC) was performed on silica gel plates precoated with a fluorescent indicator. Purity (\%) was determined with a Waters Alliance 2695 HPLC with a 2996 diode array detector from 210-400 nm.

Native gel electrophoresis. Electrophoresis was performed using a PhastSystem with PhastGel native buffer strips. Separations were performed using $20 \%$ polyacrylamide gels. After separation, gels were developed on the PhastSystem using Coomassie Blue as previously described. ${ }^{8,15}$ For the gel shift screen of test compounds with PaPBGS, samples were prepared by mixing $8 \mu \mathrm{L}$ of protein ( $1 \mathrm{mg} / \mathrm{mL}, \sim 30 \mu \mathrm{M}$ subunits) in $0.1 \mathrm{M}$ Bis-Tris propane-HCl, $\mathrm{pH} 8.5$, with $2 \mu \mathrm{L}$ of $10 \mathrm{mM}$ compound in DMSO. The resultant samples, which contained 20\% DMSO and $2 \mathrm{mM}$ compound, were incubated at $37^{\circ} \mathrm{C}$ for $30 \mathrm{~min}$ before loading and running the gels. For the native PAGE experiments containing the PBGS substrate 5-aminolevulinic acid (ALA), the gel samples were prepared with the ALA and compounds were both present for the duration of the incubation.

Thiophene-2-carbothioic acid S-\{5-[(thiophene-2-carbonyl)-amino]-[1,3,4]thiadiazol-2-yl\} ester 9. The thiadiazole 5 (500 mg, $3.68 \mathrm{mmol}$ ) was suspended in $\mathrm{CH}_{2} \mathrm{Cl}_{2}$ at room temperature, and treated with $\mathrm{Et}_{3} \mathrm{~N}(1.28 \mathrm{ml}, 9.2 \mathrm{mmol}, 2.5 \mathrm{eq})$ and thiophene-2-carbonyl chloride $(0.86 \mathrm{~mL}$, $8.1 \mathrm{mmol}, 2.2 \mathrm{~mol}$. equiv). The mixture was stirred at this temperature over a weekend to give a yellow suspension. Water $(5 \mathrm{~mL})$ and sat. $\mathrm{NaHCO}_{3}(5 \mathrm{~mL})$ were added, and the resulting mixture was filtered. The solid was washed with water and hot methanol, and dried in the vacuum oven. A light yellow solid (1.1 g, 84\%) was obtained; m.p. 257.6-258.8 ${ }^{\circ} \mathrm{C}$; ${ }^{1} \mathrm{H}$ NMR (400 MHz, DMSO-d $\left._{6}\right) \delta$ 7.28-7.35 (m, 1H), 7.36-7.42 (m, 1H), 8.03-8.11 (m, 1H), 8.19-8.26 (m,1H), 8.27$8.32(\mathrm{~m}, 1 \mathrm{H}), 8.32-8.40(\mathrm{~m}, 1 \mathrm{H}), 13.50(\mathrm{~s}, 1 \mathrm{H})$. HPLC purity $94.1 \%$.

\section{Compounds 7a-l}

The diacylthiadiazole 9 (212 mg, $0.6 \mathrm{mmol})$ was suspended in THF $(6.5 \mathrm{~mL})$ at $0{ }^{\circ} \mathrm{C}$, and treated with lithium hydroxide $(1 M, 2.1 \mathrm{~mL}, 3.5 \mathrm{~mol}$. equiv). A homogenous solution was observed after addition of the base. The reaction was monitored by TLC (EtOAc:hexane, 1:1, UV). After the starting material 9 was consumed, the mixture was evenly distributed into three vials that 
contained different halides $(0.25 \mathrm{mmol})$. The resulting mixture was left on a shaker until the thiol 6 was consumed, as shown by TLC (EtOAc:hexanes, 1:1, UV). If there was a precipitate, the solid was filtered, washed with water and methanol, and dried to provide the final product; if it was a clear solution, the mixture was partitioned between EtOAc and water. The organic phase was concentrated to give a crude product which was purified either by crystallization from EtOAc:hexanes or preparative TLC to afford the corresponding product.

Thiophene-2-carboxylic acid [5-[4-(methanesulfonyl)benzylsulfanyl]-[1,3,4]thiadiazol-2-yl]amide 7a. Yield, 51\%; white solid; m.p. 262.2-263 ${ }^{\circ} \mathrm{C} ;{ }^{1} \mathrm{H}$ NMR (400-MHz, DMSO-d 6 ) $\delta 3.20$ (s, 3H), 4.63 (s, 2H), 7.25-7.30 (m, 1H), 7.67-7.73 (m, 2H), 7.86-7.93 (m, 2H), 7.98-8.04 (m, $1 \mathrm{H})$, 8.20-8.30 (br s, $1 \mathrm{H}), 13.25$ (s, $1 \mathrm{H}$ ). HRMS (EI) Calcd for $\mathrm{C}_{15} \mathrm{H}_{14} \mathrm{~N}_{3} \mathrm{O}_{3} \mathrm{~S}_{4}(\mathrm{M}+\mathrm{H}), 411.9918$; Found, 411.9930. HPLC purity 99.4\%.

Thiophene-2-carboxylic acid [5-(3,4-dimethoxypyridin-2-ylmethylsulfanyl)-[1,3,4]thiadiazol -2-yl]-amide 7b. Yield 58\%; light yellow solid; m.p. 233.6-234.0 ${ }^{\circ} \mathrm{C}$; ${ }^{1} \mathrm{H}$ NMR (500-MHz, $\left.\mathrm{DMSO}_{-} \mathrm{d}_{6}\right) \delta 3.82$ (s, 3H), 3.91 (s, 3H), 4.59 (s, 2H), 7.06-7.18 (s, 1H), 7.24-7.32 (m, 1H), 7.98$8.04(\mathrm{~m}, 1 \mathrm{H}), 8.06-8.33(\mathrm{~m}, 2 \mathrm{H}), 13.30$ (s, 1H). HRMS (EI) Calcd for $\mathrm{C}_{15} \mathrm{H}_{15} \mathrm{~N}_{4} \mathrm{O}_{3} \mathrm{~S}_{3}(\mathrm{M}+\mathrm{H})$, 395.0306; Found, 395.0298. HPLC purity 93.1\%.

Thiophene-2-carboxylic acid [5-(4-pyrazol-1-yl-benzylsulfanyl)-[1,3,4]thiadiazol-2-yl]amide 7c. Yield, 54\%; light yellow solid; m.p. 244.6-245.6 ${ }^{\circ} \mathrm{C} .{ }^{1} \mathrm{H}$ NMR (500-MHz, DMSO-d 6 ) $\delta 4.58$ (s, 2H), 6.55 (s, 1H), 7.26-7.31 (m, 1H), 7.52-7.59 (m, 2H), $7.74(\mathrm{~s}, 1 \mathrm{H}), 7.78-7.85$ (m, 2H), 7.98-8.06 (m, 1H), 8.20-8.34 (br s, 1H), 8.47-8.52 (m, 1H), 13.25 (s, 1H). HRMS (EI) Calcd for $\mathrm{C}_{17} \mathrm{H}_{14} \mathrm{~N}_{5} \mathrm{OS}_{3}(\mathrm{M}+\mathrm{H})$, 400.0360; Found, 400.0355. HPLC purity $97.7 \%$.

Thiophene-2-carboxylic acid [5-[2-(2-fluorophenyl)-5-methyloxazol-4-ylmethylsulfonyl][1,3,4]thiadiazol-2-yl]-amide 7d. Yield, 73\%; white solid; m.p. 247.2-248.0 ${ }^{\circ} \mathrm{C} ;{ }^{1} \mathrm{H}$ NMR (500MHz, DMSO-d $\left.\mathrm{d}_{6}\right) \delta 2.39$ (s, 3H), 4.45 (s, 2H), 7.26-7.31 (m, 1H), 7.32-7.43 (m, 2H), 7.52-7.60 (m, 1H), 7.92-7.99 (m, 1H), 8.00-8.06 (m, 1H), 8.20-8.37 (br s, 1H), 13.22 (s, 1H). HRMS (EI) Calcd for $\mathrm{C}_{18} \mathrm{H}_{14} \mathrm{FN}_{4} \mathrm{O}_{2} \mathrm{~S}_{3}(\mathrm{M}+\mathrm{H})$, 433.0263; Found, 433.0259. HPLC purity $100 \%$.

Thiophene-2-carboxylic acid [5-[3-(2,6-dichloro-phenyl)-5-methylisoxazol-4-ylmethylsulfanyl]-[1,3,4]thiadiazol-2-yl]-amide 7e. Yield, 57\%; white solid; m.p. 237.0-238.0 ${ }^{\circ} \mathrm{C} ;{ }^{1} \mathrm{H}$ NMR $\left(300-\mathrm{MHz}, \mathrm{CDCl}_{3}\right) \delta 2.47$ (s, 3H), 4.18 (s, 2H), 7.14 (dd, $\left.J=5.1,4.2 \mathrm{~Hz}, 1 \mathrm{H}\right), 7.30-7.44$ (m, 3H), 7.70 (dd, $J=5.1,0.9 \mathrm{~Hz}, 1 \mathrm{H}$ ), 8.24 (dd, $J=3.9,4.2 \mathrm{~Hz}, 1 \mathrm{H}), 12.0$ (s, 1H). HRMS (EI) Calcd for $\mathrm{C}_{18} \mathrm{H}_{13} \mathrm{Cl}_{2} \mathrm{~N}_{4} \mathrm{O}_{2} \mathrm{~S}_{3}(\mathrm{M}+\mathrm{H})$, 482.9578; Found, 482.9421. HPLC purity $100 \%$.

Thiophene-2-carboxylic acid [5-(7-methylimidazo[1,2-a]pyridin-2-ylmethylsulfanyl)-[1,3,4] thiadiazol-2-yl]-amide 7f. Yield, 82\%; light brown solid; m.p. 233.6-234.6 ${ }^{\circ} \mathrm{C}$; Mixture of conformers, ${ }^{1} \mathrm{H}$ NMR (500-MHz, DMSO-d 6 ) $\delta 2.31$ (s, 0.86H), 2.34 (s, 2.14H), $4.58(\mathrm{~s}, 1.50 \mathrm{H})$, 4.77 (s, 0.5H), 6.71-6.75 (m, 0.75 H), 6.85-6.88 (m, 0.25H), 7.25-7.31 (m, 1.75H), 7.36-7.38 (s, 0.25H), 7.82 (s, $1 \mathrm{H}), 8.00-8.04(\mathrm{~m}, 1 \mathrm{H}), 8.25-8.31(\mathrm{~m}, 1 \mathrm{H}), 8.37-8.42(\mathrm{~m}, 0.75 \mathrm{H}), 8.50-8.55$ (m, $0.25 \mathrm{H}), 13.30$ (s, $1 \mathrm{H})$. HRMS (EI) Calcd for $\mathrm{C}_{16} \mathrm{H}_{14} \mathrm{~N}_{5} \mathrm{OS}_{3}(\mathrm{M}+\mathrm{H})$, 388.0360; Found, 388.0365. HPLC purity $91.0 \%$.

Thiophene-2-carboxylic acid [5-(2-chloro-4-fluorobenzylsulfanyl)-[1,3,4]thiadiazol-2-yl]amide 7g. Yield, 50\%; white solid; m.p.257.2-258.0 ${ }^{\circ} \mathrm{C} ;{ }^{1} \mathrm{H}$ NMR (500-MHz, DMSO-d 6 ) $\delta 4.58$ 
(s, 2H), 7.18-7.26 (m, 1H), 7.26-7.33 (m, 1H), 7.50-7.55 (m, 1H), 7.55-7.63 (m, 1H), 7.96-8.08 (m, 1H), 8.20-8.39 (br s, 1H), 13.26 (s, 1H). HRMS (EI) Calcd for $\mathrm{C}_{14} \mathrm{H}_{10} \mathrm{ClFN}_{3} \mathrm{OS}$ (M+H), 385.9659; Found, 388.0365. HPLC purity 95.0\%.

Thiophene-2-carboxylic acid [5-[3-(4-fluoro-phenoxy)-benzylsulfanyl]-[1,3,4]thiadiazol-2yl]-amide 7h. Yield, 52\%; white solid; m.p. 201.4-202.4 ${ }^{\circ} \mathrm{C} ;{ }^{1} \mathrm{H}$ NMR (500-MHz, DMSO-d 6 ) $\delta$ 4.43 (s, 2H), 6.87-6.92 (m, 1H), 6.99 (s, 1H), 7.01-7.07 (m, 2H), 7.16-7.27 (m, 4H), 7.32-7.38 (m, 1H), 7.87-7.98 (br s, 1H), 8.06-8.22 (br s, 1H), 13.28 (s, 1H). HRMS (EI) Calcd for $\mathrm{C}_{20} \mathrm{H}_{15} \mathrm{FN}_{3} \mathrm{O}_{2} \mathrm{~S}_{3}(\mathrm{M}+\mathrm{H})$, 444.0310; Found, 444.0329. HPLC purity $100 \%$.

Thiophene-2-carboxylic acid [5-(2-methyl-thiazol-4-ylmethylsulfanyl)-[1,3,4]thiadiazol-2yl]-amide 7i. Yield, 68\%; white solid; m.p. 192.3-193.2 ${ }^{\circ} \mathrm{C} ;{ }^{1} \mathrm{H}$ NMR (400-MHz, DMSO-d 6 ) $\delta$ 2.64 (s, 3H), 4.53 (s, 2H), 7.23-7.29 (m, 1H), 7.39 (s, 1H), 7.94-8.01 (m, 1H), 8.15-8.26 (br m, $1 \mathrm{H}), 13.25$ (s, 1H). HRMS (EI) Calcd for $\mathrm{C}_{12} \mathrm{H}_{11} \mathrm{~N}_{4} \mathrm{OS}_{4}(\mathrm{M}+\mathrm{H}), 354.9816$; Found, 354.9812. HPLC purity $99.6 \%$.

Thiophene-2-carboxylic acid [5-[2-(4-chlorophenyl)thiazol-4-ylmethylsulfanyl]-[1,3,4]thiadiazol-2-yl]-amide 7j. Yield, 95\%; white solid; m.p. 257.2-258.0 ${ }^{\circ} \mathrm{C}$; ${ }^{1} \mathrm{H}$ NMR (300-MHz, $\mathrm{DMSO}_{6}$ ) $\delta 4.64$ (s, 2H), 7.26 (dd, $\left.J=5.1,3.9 \mathrm{~Hz}, 1 \mathrm{H}\right), 7.51-7.58(\mathrm{~m}, 2 \mathrm{H}), 7.66(\mathrm{~s}, 1 \mathrm{H}), 7.91-$ 7.97 (m, 2H), 7.99 (br d, $J=5.1 \mathrm{~Hz}, 1 \mathrm{H}$ ), 8.22-8.34 (m, 1H), 13.24 (s, 1H). HRMS (EI) Calcd for $\mathrm{C}_{17} \mathrm{H}_{12} \mathrm{ClN}_{4} \mathrm{OS}_{4}(\mathrm{M}+\mathrm{H})$, 450.9582; Found, 450.9578. HPLC purity $96.4 \%$.

Thiophene-2-carboxylic acid [5-[2-(4-trifluoromethyl-phenyl)-thiazol-4-ylmethylsulfanyl][1,3,4]thiadiazol-2-yl]-amide 7k. Yield, 51\%; white solid; m.p. 268.1-268.7 ${ }^{\circ} \mathrm{C}$; ${ }^{1} \mathrm{H}$ NMR (400MHz, DMSO-d $\left.{ }_{6}\right) \delta 4.69$ (s, 2H), 7.25-7.32 (m, 1H), 7.78 (s, 1H), 7.82-7.90 (m, 2H), 7.99-8.06 $(\mathrm{m}, 1 \mathrm{H}), 8.11-8.19(\mathrm{~m}, 2 \mathrm{H}), 8.22-8.36$ (br s, 1H), 13.25 (s, 1H). HRMS (EI) Calcd for $\mathrm{C}_{18} \mathrm{H}_{12} \mathrm{~F}_{3} \mathrm{~N}_{4} \mathrm{OS}_{4}(\mathrm{M}+\mathrm{H})$, 484.9846; Found, 484.9861. HPLC purity $100 \%$.

Thiophene-2-carboxylic acid [5-[4-(5-methyl-isoxazol-3-ylcarbamoyl)-benzylsulfanyl][1,3,4]thiadiazol-2-yl]-amide 7l. Yield, 55\%; white solid; m.p. 287.2-288.0 ${ }^{\circ} \mathrm{C} ;{ }^{1} \mathrm{H}$ NMR (400MHz, DMSO-d $\left.\mathrm{d}_{6}\right) \delta 2.48(\mathrm{~s}, 3 \mathrm{H}), 4.68(\mathrm{~s}, 2 \mathrm{H}), 6.81(\mathrm{~s}, 1 \mathrm{H}), 7.30-7.37(\mathrm{~m}, 1 \mathrm{H}), 7.60-7.68(\mathrm{~m}$, 2H), 8.00-8.06 (m, 2H), 8.06-8.13 (m, 1H), 8.27-8.42 (br s, 1H), 13.28 (s, 1H). HRMS (EI) Calcd for $\mathrm{C}_{19} \mathrm{H}_{16} \mathrm{~N}_{5} \mathrm{O}_{3} \mathrm{~S}_{3}(\mathrm{M}+\mathrm{H})$, 458.0415; Found, 458.0408. HPLC purity $99.0 \%$.

\section{Acknowledgements}

We thank Drs. Trevor Selwood and Sarah Lawrence of the Fox Chase Cancer Center. We acknowledge the following National Institutes of Health grant support of this work: NIAID R21AI063324 (EKJ) and R43AI084224 (ABR), and NCI T32CA009035 (ICR) and P30CA006927 (FCCC). 


\section{References}

1. Munos, B. Nat. Rev. Drug Disc. 2009, 8, 959.

2. http://www.fiercebiotech.com/slideshows/fda-approvals-2009.

3. For recent publications, see (a) Parker, M. H.; Smith-Swintosky, V. L.; McComsey, D. F.; Huang, Y.; Brenneman, D.; Klein, B.; Malatynska, E.; White, H. S.; Milewski, M. E.; Herb, M.; Finley, M. F. A.; Liu, Y.; Lubin, M. L.; Qin, N.; Iannucci, R.; Leclercq, L.; Cuyckens, F.; Reitz, A. B.; Maryanoff, B. E. Novel J. Med. Chem. 2009, 52, 7528. (b) Cejas, M. A.; Kinney, W. A.; Chen, C.; Vinter, J. C.; Almond, H. R., Jr.; Balss, K. M.; Maryanoff, C. A.; Schmidt, U.; Breslav, M.; Mahan, A.; Lacy, E.; Maryanoff, B. E. Proc. Natl. Acad. Sci. 2008, 105, 8513.

4. Ryan, K. J.; Ray, C. G., Ahmad, N.; Drew, L.; Plorde, J. J. Eds Sherris Medical Microbiology (5th Ed.), McGraw-Hill, New York, 2010.

5. http://textbookofbacteriology.net/pseudomonas.html, Todar, K., 2008.

6. Jaffe, E. K. Trends Biochem. Sci. 2005, 30, 490.

7. Tang, L.; Stith, L.; Jaffe, E. K. J. Biol. Chem. 2005, 280, 15786.

8. Lawrence, S. H.; Ramirez, U. D.; Tang, L.; Fazliyez, F.; Kundrat, L.; Markham, G. D.; Jaffe, E. K. Chem. Biol. 2008, 15, 586.

9. Johnson, S. M.; Connelly, S.; Wilson, I. A.; Kelly, J. W. J. Med. Chem. 2008, 51, 260, and references cited therein.

10. Sadlon, T. J.; Dell'Oso, T.; Surinya, K. H.; May, B. K. Int. J. Biochem. Cell Biol. 1999, 31, 1153.

11. Cornah, J. E.; Terry, M. J.; Smith, A. J. Trends Plant Sci. 2003, 8, 224.

12. Petrovich, R. M.; Litwin, S.; Jaffe, E. K. J. Biol. Chem. 1996, 271, 8692.

13. Kervinen, J.; Dunbrack, R. L., Jr.; Litwin, S.; Martins, J.; Scarrow, R. C.; Volin, M.; Yeung, A. T.; Yoon, E.; Jaffe, E. K. Biochemistry 2000, 39, 9018.

14. Jaffe, E. K. Chem. Biol. 2003, 10, 25.

15. Kokona, B.; Rigotti, D. J.; Wasson, A. S.; Lawrence, S. H.; Jaffe, E. K.; Fairman, R. Biochemistry 2008, 47, 10649.

16. Tang, L.; Breinig, S.; Stith, L.; Mischel, A.; Tannir, J.; Kokona, B.; Fairman, R.; Jaffe, E. K. J. Biol. Chem. 2006, 281, 6682.

17. Tang, L.; Stith, L.; Jaffe, E. K. J. Biol. Chem. 2005, 280, 15786.

18. Breinig, S.; Kervinen, J.; Stith, L.; Wasson, A. S.; Fairman, R.; Wlodawer, A.; Zdanov, A.; Jaffe, E. K. Nat. Struct. Biol. 2003, 10, 757.

19. Frankenberg, N.; Erskine, P. T.; Cooper, J. B.; Shoolingin-Jordan, P. M.; Jahn, D.; Heinz, D. W. Mol. Biol. 1999, 289, 591.

20. Erskine, P.T.; Senior, N.; Awan, S.; Lambert, R.; Lewis, G.; Tickle, I. J.; Sarwar, M.; Spencer, P.; Thomas, P.; Warren, M. J.; Shoolingin-Jordan, P. M.; Wood, S. P.; Cooper, J. B. Nat. Struct. Biol. 1997, 4, 1025.

21. Jaffe, E. K. Acta Crystallogr. D Biol. Crystallogr. 2000, 56 (Pt 2): 115. 
22. Ramirez, U. D.; Myachina, F.; Stith, L.; Jaffe, E. K. in Hamid, A., Ed., Advances in Computational Biology, Proceedings of the 2009 International Conference on Bioinformatics and Computational Biology, Series: Advances in Experimental Medicine and Biology, in press, 2010.

23. Lawrence, S. H.; Ramirez, U. D.; Selwood, T.; Stith, L.; Jaffe, E. K. J. Biol. Chem. 2009. 284, 35807.

24. Friesner, R. A.; Banks, J. L.; Murphy, R. B.; Halgren, T. A.; Klicic, J. J.; Mainz, D. T.; Repasky, M. P.; Knoll, E. H.; Shelley, M.; Perry, J. K.; Shaw, D. E.; Francis, P.; Shenkin, P. S. J. of Med. Chem. 2004, 47, 1739.

25. Selwood, T.; Tang, L.; Lawrence, S. H.; Anokhina, Y.; Jaffe, E. K. Biochemistry 2008, 47, 3245.

26. Jaffe, E. K.; Ali, S.; Mitchell, L. W.; Taylor, K. M.; Volin, M.; Markham, G. D. Biochemistry 1995, 34, 244.

27. Reitz, A. B.; Smith, G. R.; Tounge, B. A.; Reynolds, C. A. Curr. Top. Med. Chem. 2009, 9, 1718.

28. Clerici, F.; Pocar, D.; Guido, M.; Loche, A.; Perlini, V.; Brufani, M. J. Med. Chem. 2001, 44, 931. 